\title{
DRY AND WET ETCHING FOR GROUP III - NITRIDES
}

\author{
I. Adesida, C. Youtsey, A. T. Ping, F. Khan, L. T. Romano,* and G. Bulman** \\ Department of Electrical and Computer Engineering, University of Illinois, Urbana-Champaign, IL \\ 61801 \\ *Xerox PARC, Palo Alto, CA 94304 \\ ** CREE Research, Inc.,Durham, NC 27713
}

MRS Internet J. Nitride Semiconductor Res. 4S1, G1.4 (1999)

\begin{abstract}
The group-III nitrides have become versatile semiconductors for short wavelength emitters, high temperature microwave transistors, photodetectors, and field emission tips. The processing of these materials is significant due to the unusually high bond energies that they possess. The dry and wet etching methods developed for these materials over the last few years are reviewed. High etch rates and highly anisotropic profiles obtained by inductively-coupled-plasma reactive ion etching are presented. Photoenhanced wet etching provides an alternative path to obtaining high etch rates without ion-induced damage. This method is shown to be suitable for device fabrication as well as for the estimation of dislocation densities in $\mathrm{n}-\mathrm{GaN}$. This has the potential of developing into a method for rapid evaluation of materials.
\end{abstract}

\section{INTRODUCTION}

The success of the synthesis and growth of the wide bandgap group-III nitrides over the last decade has made the realization of a wide range of new devices possible. The bandgap energies of the III-nitrides range from $1.9 \mathrm{eV}$ for InN to $3.4 \mathrm{eV}$ for $\mathrm{GaN}$ to $6.2 \mathrm{eV}$ for AlN. Using these materials, bright light emitting diodes (LEDs) and laser diodes (LDs) [1,2] operating at short wavelengths have been demonstrated. Indeed, LDs with InGaN/AlGaN active layers having lifetimes greater than 10,000 hours have been demonstrated making the commercialization of these devices a certainty. The excellent electron transport characteristics of GaN coupled with the wide bandgap, the chemical stability, and the availability of $\mathrm{AlGaN} / \mathrm{GaN}$ heterostructures also make III-nitrides suitable for high power, high temperatures transistors. $\mathrm{AlGaN} / \mathrm{GaN}$ heterostructure field effect transistors (HFETs) on sapphire operating at frequencies greater than $70 \mathrm{GHz}$ have been demonstrated [3] and similar HFETs grown on $\mathrm{SiC}$ exhibiting power densities as high as $6.8 \mathrm{~W} / \mathrm{mm}$ have also been fabricated [4]. Most recently, $\mathrm{AlGaN} / \mathrm{GaN}$ heterojunction bipolar transistors have been demonstrated [5].

Improvements in the performance of these devices depend on the quality of epitaxial materials and the development of device processing technologies. In particular, effective etching techniques are essential for forming facets for GaN LDs, defining mesas for photodetectors, and gate recessing for HFETs. Group-III nitrides have high bond energies compared to conventional III-V semiconductors. The bond energies are $7.7 \mathrm{eV} /$ atom for InN, $8.9 \mathrm{eV} /$ atom for $\mathrm{GaN}$, and $11.5 \mathrm{eV} /$ atom for AlN compared to $6.5 \mathrm{eV} /$ atom for GaAs. The high bond strengths and wide bandgaps make them essentially chemically inert and highly resistant to bases and acids at room temperature. Therefore a wide range of dry and wet etching techniques have been investigated for the processing of III-nitrides. Since bond strengths are high for the III-nitrides, external energy is required to initiate and sustain the dissociation of the bonds. Sources of external energy include energetic ions, energetic electrons, and optical radiation for different 
etching methods. In this paper, we present these etching methods and discuss the progress made in applying some of them to III-nitrides.

\section{DRY ETCHING}

Various methods of dry etching involving ion-assisted mechanisms have been applied to the processing of III-nitrides. They include ion milling [6,7], chemically assisted ion beam etching (CAIBE) $[8,9,55]$, reactive ion beam etching (RIBE) [10], reactive ion etching (RIE) [11-15], electron-cyclotronresonance reactive ion etching (ECR-RIE) [16-21], and inductively-coupled-plasma reactive ion etching (ICP-RIE) [22-27]. Optical excitation sources with photon energies higher than the bandgap energies of the semiconductors have been applied to both dry and wet etching methods. The photoassisted dryetching method [28] involves optical radiation of the sample in the presence of reactive gases. Low energy electron-enhanced etching (LE4) [29] is a dry etching method where electrons with energies $<15$ $\mathrm{eV}$ are the source of external energy.

Ion milling rely on physical sputtering to achieve etching but this method is not practical for nitrides because of low etch rates and high ion-induced damage [6,7]. Therefore, methods of dry etching involving chemical mechanisms in addition to physical sputtering are the most effective for device applications. Of these techniques, the CAIBE, RIE, ECR-RIE, and ICP-RIE have been the most widely investigated. Tools for ECR-RIE and ICP-RIE are high-density-plasma systems which use magnetic confinement of electrons to generate very high ion densities $\left(>5 \times 10^{11} \mathrm{~cm}^{-3}\right)$. Although, the methods for coupling power to the plasma in these systems are different, the plasmas have similar properties. It should also be noted that in these systems the rf power generators for controlling the ion flux and for fixing the ion energy are different. This de-coupling allows for the delivery of large ion fluxes at low energies (or biases) onto samples. This enhances etch rates and prevents excessive lattice damage in comparison to conventional RIE.

\section{Etch Rates and Profiles}

The chemistries for the dry etching of III-nitrides are mostly halogen-based with the most prevalent being chlorine-based. A summary of some of these chemistries along with the etching methods and accompanying etch rates are presented in Table I. It should be noted that a direct comparison of the etch rates in Table I cannot be made since material quality and etching apparatus can differ significantly.

The plasma chemistries in Table I are identical to those utilized for conventional compound semiconductors. It should be expected that etch products for the group-III elements should therefore be similar in both cases. For nitrides etched in Cl-based gases, the etch-products are $\mathrm{GaCl}_{\mathrm{x}}, \mathrm{InCl}_{\mathrm{x}}$, and $\mathrm{AlCl}_{\mathrm{x}}$ for the Group III elements, while for nitrogen, it could be $\mathrm{NCl}_{3}$ or perhaps free $\mathrm{N}_{2}$. The volatility of these products is aided by ion bombardment. However, with the boiling point of $\mathrm{InCl}_{3}$ being high at $600{ }^{\circ} \mathrm{C}$, other gas mixtures involving $\mathrm{CH}_{4}$ have been investigated. The potential products for these mixtures are methyl- or ethyl-based metal-organics for the metals along with $\mathrm{NH}_{3}$ for nitrogen. The boiling point of $\left(\mathrm{CH}_{3}\right)_{3} \mathrm{Ga},\left(\mathrm{CH}_{3}\right)_{3} \mathrm{In}$, and $\left(\mathrm{CH}_{3}\right)_{3} \mathrm{Al}$ are $<150{ }^{\circ} \mathrm{C}$, and are therefore, more readily volatile. Notwithstanding the similarities in terms of etch chemistries, we note that the high bond energies of the nitrides degrade their etch rates in comparison to those of other compound semiconductors.

The etch rates reported for GaN using RIE with various etch chemistries range from 17 to 100 $\mathrm{nm} / \mathrm{min}$ [11-15]. Etch rates were found to depend strongly on the plasma self-bias voltage, and essentially independent of the chamber pressure for pressures less than $80 \mathrm{mTorr}$ [13]. The higher etch rates were obtained at high plasma dc biases from -300 to $-400 \mathrm{~V}$. Anisotropic etch profiles were obtained in all cases but they were overcut which meant that physical mechanisms dominated the etching. In conventional RIE, physical and chemical components of etching cannot be independently 
controlled. This impacts the shape of etch profiles significantly especially in the case of III-nitrides where high ion energy is required to break the bonds.

Table I. Summary of etch rates for various dry etching methods.

\begin{tabular}{|c|c|c|c|c|c|c|}
\hline \multirow[t]{2}{*}{ Gas Chemistry } & \multirow{2}{*}{$\begin{array}{l}\text { Etching } \\
\text { Technique }\end{array}$} & \multicolumn{5}{|c|}{ Etch Rate (nm/min) } \\
\hline & & GaN & & AlN & & InN \\
\hline Ar & Ion Milling & $110 \quad 500 \mathrm{eV}^{6}$ & 29 & $500 \mathrm{eV}^{7}$ & 61 & $500 \mathrm{eV}^{7}$ \\
\hline $\mathrm{HCl}$ [Ar ion] & CAIBE & $500 \mathrm{eV}^{8}$ & - & -- & -- & - - - \\
\hline $\mathrm{Cl}_{2}$ [Ar ion] & CAIBE & $500 \mathrm{eV}^{9}$ & 62 & $500 \mathrm{eV}^{55}$ & - & - \\
\hline $\mathrm{HCl}$ & RIBE & $500 \mathrm{eV}^{10}$ & - & - & - & - \\
\hline $\mathrm{Cl}_{2}$ & RIBE & $500 \mathrm{eV}^{10}$ & - & - & - & -- \\
\hline $\mathrm{SF}_{6}$ & RIE & $-400 \mathrm{~V}^{11}$ & - & -- & - & -- \\
\hline $\mathrm{CHF}_{3}, \mathrm{C}_{2} \mathrm{ClF}_{5}$ & RIE & $500 \mathrm{~W}^{12}$ & - & - & - & - \\
\hline $\mathrm{SiCl}_{4}\left[\mathrm{w} / \mathrm{Ar}, \mathrm{SiF}_{4}\right]$ & RIE & $-400 V^{13}$ & -- & -- & - & - \\
\hline $\mathrm{HBr}\left[\mathrm{w} / \mathrm{Ar}, \mathrm{H}_{2}\right]$ & RIE & $-400 \mathrm{~V}^{14}$ & - & - & - & - \\
\hline $\mathrm{BCl}_{3}$ & RIE & $-230 V^{15}$ & - & 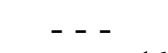 & - & - - - \\
\hline $\mathrm{CH}_{4} / \mathrm{H}_{2} / \mathrm{Ar}$ & ECR-RIE & $-250 \mathrm{~V}^{16}$ & 2.5 & $-300 V^{16}$ & 10 & $-300 V^{16}$ \\
\hline $\mathrm{CCl}_{2} \mathrm{~F}_{2} / \mathrm{Ar}$ & ECR-RIE & $-250 \mathrm{~V}^{16}$ & 18 & $-300 V^{16}$ & 18 & $-300 V^{16}$ \\
\hline $\mathrm{BCl}_{3} / \mathrm{Ar}$ & ECR-RIE & $-250 \mathrm{~V}^{16}$ & 17 & $-250 \mathrm{~V}^{16}$ & 17 & $-300 V^{16}$ \\
\hline $\mathrm{HBr} / \mathrm{H}_{2}$ & ECR-RIE & $-150 \mathrm{~V}^{17}$ & 65 & $-150 \mathrm{~V}^{17}$ & 17 & $-150 \mathrm{~V}^{17}$ \\
\hline $\mathrm{SiCl}_{4} / \mathrm{Ar}$ & ECR-RIE & $-280 \mathrm{~V}^{18}$ & - & - - - & -- & - - \\
\hline $\mathrm{HI} / \mathrm{H}_{2}$ & ECR-RIE & $-150 \mathrm{~V}^{17}$ & 120 & $-150 \mathrm{~V}^{17}$ & 100 & $-150 \mathrm{~V}^{17}$ \\
\hline $\mathrm{Cl}_{2} / \mathrm{H}_{2} / \mathrm{Ar}$ & ECR-RIE & $-180 \mathrm{~V}^{19}$ & 110 & $-150 \mathrm{~V}^{19}$ & 150 & $-180 \mathrm{~V}^{19}$ \\
\hline $\mathrm{IBr} / \mathrm{Ar}$ & ECR-RIE & $-170 \mathrm{~V}^{20}$ & 160 & $-170 V^{20}$ & 325 & $-170 \mathrm{~V}^{20}$ \\
\hline $\mathrm{ICl} / \mathrm{Ar}$ & ECR-RIE & $-275 \mathrm{~V}^{21}$ & 200 & $-275 V^{21}$ & 1150 & $-275 V^{21}$ \\
\hline $\mathrm{Cl}_{2} / \mathrm{N}_{2}$ & ICP-RIE & $-100 \mathrm{~V}^{22}$ & 39 & $-100 V^{22}$ & 30 & $-100 V^{22}$ \\
\hline $\mathrm{Cl}_{2} / \mathrm{SF}_{6}$ & ICP-RIE & $-250 \mathrm{~V}^{23}$ & 184 & $-250 \mathrm{~V}^{23}$ & 46 & $-250 \mathrm{~V}^{23}$ \\
\hline $\mathrm{CH}_{4} / \mathrm{H}_{2} / \mathrm{Ar}$ & ICP-RIE & $-620 \mathrm{~V}^{24}$ & 30 & $-100 \mathrm{~V}^{24}$ & 110 & $-480 V^{24}$ \\
\hline $\mathrm{Cl}_{2} / \mathrm{Ar} / \mathrm{H}_{2}$ & ICP-RIE & $-280 \mathrm{~V}^{25}$ & - & - - - & -- & - - - \\
\hline $\mathrm{BCl}_{3} / \mathrm{Cl}_{2}$ & ICP-RIE & $-120 \mathrm{~V}^{26}$ & - & - - - & - & - - \\
\hline $\mathrm{Cl}_{2} / \mathrm{Ar}$ & ICP-RIE & $980-450 \mathrm{~V}^{27}$ & 670 & $-450 \mathrm{~V}^{27}$ & 150 & $-100 \mathrm{~V}^{22}$ \\
\hline $\mathrm{HCl}$ & Photoassisted & $0.004 \mathrm{~nm} /$ pulse $^{28}$ & -- & - - - & - & - - \\
\hline $\mathrm{H}_{2} / \mathrm{Cl}_{2}$ & LE4 & $50-70 \quad 1-15 \mathrm{eV}^{29}$ & - & -- & - & -- \\
\hline
\end{tabular}

In CAIBE, an ion beam is directed onto a sample in a reactive gas ambient. The ion energy and beam current can be controlled while the flow of the reactive gas can also be controlled. Therefore, the physical and chemical etching components can be controlled independently. Adesida et al. [9] have characterized CAIBE etching using $\mathrm{Ar} / \mathrm{Cl}_{2}$. As shown in Fig. 1, the etch rates of $\mathrm{GaN}$ for $500 \mathrm{eV} \mathrm{Ar}$ and a flow of $\mathrm{Cl}_{2}$ incident on $\mathrm{GaN}$ increases with ion beam density at room temperature in curve (b). Etch rates as high as $160 \mathrm{~nm} / \mathrm{min}$ was achieved; this is enhanced in comparison to the etch rates obtained with $\mathrm{Ar}$ ion beam as shown in curve (a). The enhancement is due to the chemical component brought about by the presence of the chlorine atoms. Another enhancement is observed for CAIBE at $200{ }^{\circ} \mathrm{C}$ where it has been ascertained that the thermal energy contributed primarily to the chemical etching mechanisms. CAIBE etch rates as high as $100 \mathrm{~nm} / \mathrm{min}$ for $\mathrm{GaN}$ at room temperature have also been reported by Kneissl et al. [30]. The trend for CAIBE etch rates of GaN has strong dependence on ion density and ion energy and moderate dependence on temperature and gas flow rate. The etch rates of $\mathrm{Al}_{\mathrm{x}} \mathrm{Ga}_{1-\mathrm{x}} \mathrm{N}$ diminished linearly from $x=0$ to 1 at room temperature [9]. However, the etch rates for $x<0.1$ were not 


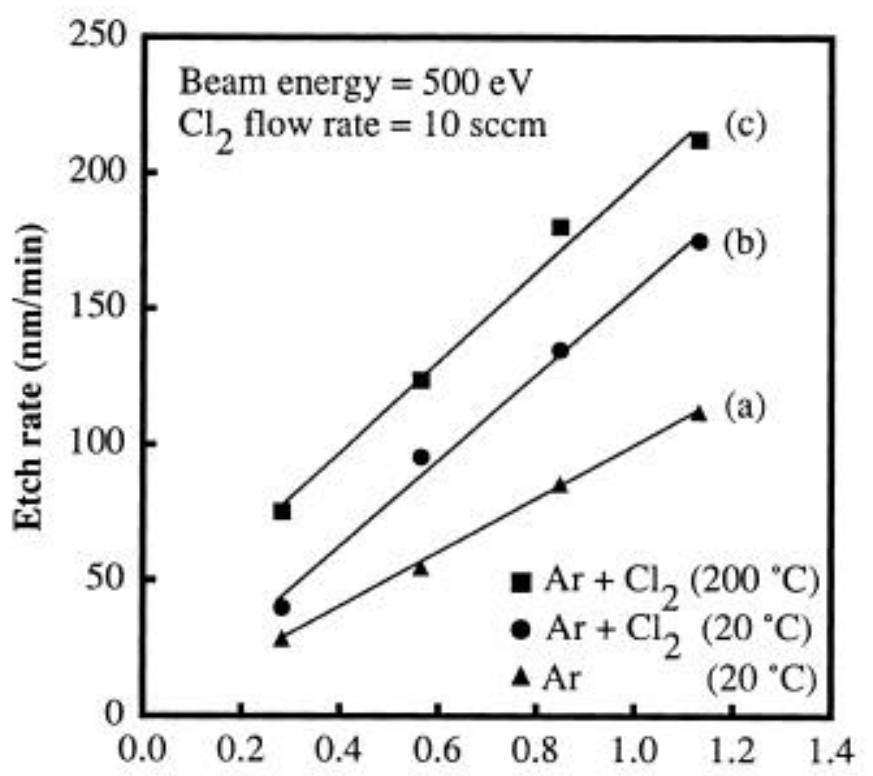

Ar ion beam current density $\left(\mathrm{mA} / \mathrm{cm}^{2}\right)$

Fig. 1. Etch rate of GaN vs Ar ion current.

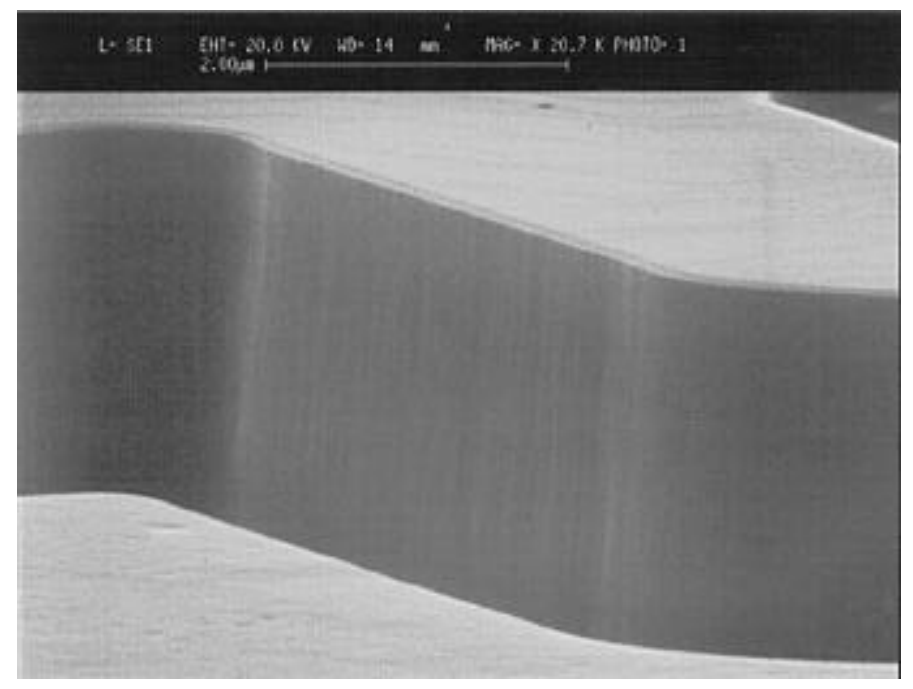

Fig. 2 GaN facet etched by CAIBE

significantly different, therefore heterostructures such as those utilized for lasers can essentially be etched at equi-etch rates. Ar/ $\mathrm{Cl}_{2} \mathrm{CAIBE}$ etching produced anisotropic but only near-vertical etch profiles [9,31] at all substrate temperatures. The profiles were more vertical at higher temperatures due to increased chemical activities during etching [8,9]. In order to achieve the verticality necessary for laser facets, Binet [31] and Kneissl et al. [30] tilted and rotated their samples while etching. InGaN/AlGaN laser diodes with CAIBE-etched facets have been fabricated and demonstrated using this method by Kneissl et al. [30]. Highly vertical etch profiles have also been obtained by Ping et al. [8] using $\mathrm{Ar} / \mathrm{HCl}$ CAIBE at $300{ }^{\circ} \mathrm{C}$ with no tilting of samples. An example of such a vertical etch-profile produced in an AlGaN/GaN heterostructure is shown in Fig. 2. The ultra-smooth sidewall demonstrated in Fig. 2 was obtained using a regrown oxide masking process [32]. The sidewall roughness was $<5 \mathrm{~nm}$ as measured in a scanning electron microscope.

High etch rates and highly anisotropic etch profiles have been obtained using high-density plasma reactive ion etching techniques. The high etch-rates produced by ECR-RIE and ICP-RIE methods are due to the higher plasma density available. The etch yields in the high-density plasma tools are the same as those in conventional RIE system, but the much larger ion fluxes in the former lead to higher etch rates. The higher efficiency of plasma generation also means that plasma can be generated and sustained in a higher vacuum environment than possible for conventional RIE tools. The independent biasing of the sample with $13.56 \mathrm{MHz}$ generator provides for the control of the energy at which ions bombard the sample in high-density plasma etching tools. The directionality of low energy ions is preserved due to higher vacuum environment. This means that anisotropy can be achieved for etch profiles at lower ion energies.

A large body of work exists for ECR-RIE etching of III-nitrides [16-21]. Various chemistries involving chlorine and methane-based gases have been investigated as shown in Table I. Etch rates for GaN ranging from 20 to $200 \mathrm{~nm} / \mathrm{min}$ have been obtained for operating pressures between 1 to $10 \mathrm{mTorr}$ and ion energies $<-300 \mathrm{~V}$. Corresponding etch rates for InN and AlN are comparable or lower than for $\mathrm{GaN}$. For example, etch rates of 200, 150, and $110 \mathrm{~nm} / \mathrm{min}$ were reported for GaN, InN, and AlN, respectively, using $\mathrm{Cl}_{2} / \mathrm{H}_{2} / \mathrm{Ar}$ plasma at a bias of $-180 \mathrm{~V}$ [19]. The inclusion of $\mathrm{H}_{2}$ in the plasma was found to increase etch rates and also improve surface morphology. This was achieved by the removal of nitrogen through the formation of $\mathrm{NH}_{\mathrm{x}}$ products. In order to obtain even higher etch rates, novel gases such as ICl/Ar, IBr/Ar have been investigated [20,21]. High etch rates of 1300, 1150, and $200 \mathrm{~nm} / \mathrm{min}$ in 
$\mathrm{ICl} / \mathrm{Ar}$ plasma have been obtained for $\mathrm{GaN}, \mathrm{InN}$, and AlN, respectively. Highly anisotropic profiles were routinely obtained using ECR-RIE.

Another high-density plasma source is the ICP-RIE. ICP-RIE sources are easier to scale up than ECR sources and are more economical to operate [25]. These factors have led to the investigation of ICP-RIE for III-nitrides in various plasmas [22-27]. As expected, high etch rates and etch profiles with high anisotropy have been demonstrated. Etch rates of $\mathrm{GaN}$ as high as $688 \mathrm{~nm} / \mathrm{min}$ at $-280 \mathrm{~V}$ [25] and $980 \mathrm{~nm} / \mathrm{min}$ at $-450 \mathrm{~V}$ [27] have been reported for $\mathrm{Cl}_{2} / \mathrm{H}_{2} / \mathrm{Ar}$ and $\mathrm{Cl}_{2} / \mathrm{Ar}$ plasmas, respectively. A GaN etch rate of $850 \mathrm{~nm}$ was obtained using $\mathrm{BCl}_{3} / \mathrm{Cl}_{2}$ plasma at $-120 \mathrm{~V}$ and $30 \mathrm{mTorr}$ [26]. Etch rates for InN, AlN, and various mole fractions of AlInN and $\mathrm{AlGaN}$ have also been reported [33]. Etch selectivities between these various materials have been reported for different gas mixtures including $\mathrm{Cl}_{2} / \mathrm{SF}_{6}$ [23]. Selectivities of 5 and 3 were reported for $\mathrm{GaN}$ on $\mathrm{AlN}$ and GaN on InN, respectively, using $\mathrm{Cl}_{2} / \mathrm{Ar}$ at $-250 \mathrm{~V}$ [34]. Corresponding selectivity results for $\mathrm{Cl}_{2} / \mathrm{SF}_{6}$ at $-250 \mathrm{~V}$ were $<1$ for GaN/AlN and 4 for $\mathrm{GaN} / \mathrm{InN}$, respectively [23]. It would be expected that the formation of AlF or InF should

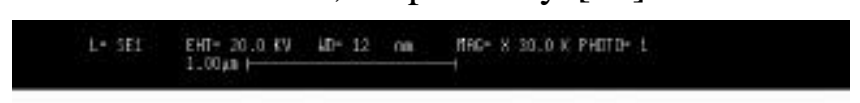
retard the etching of the AlN, InN and the ternaries, however, the dc biases used for the etching were relatively high. The high dc bias cause physical

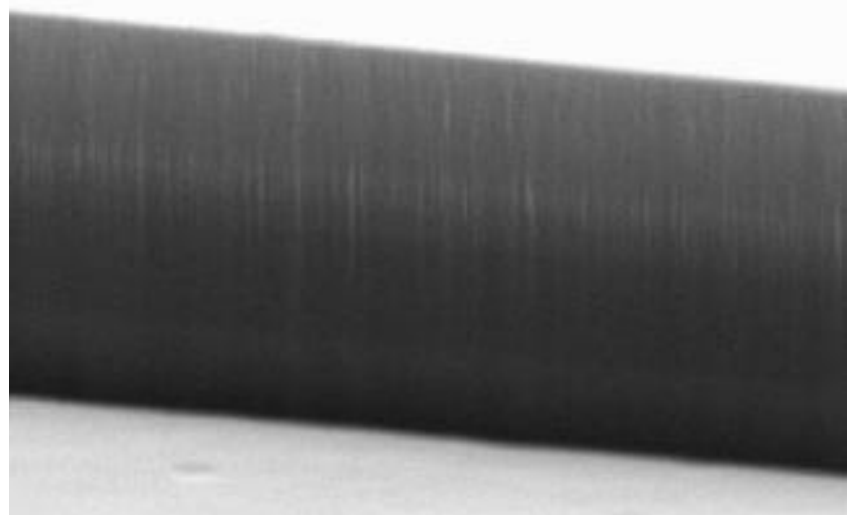

Fig. 3. InGaN/AIGaN laser facet etched by ICP-RIE sputtering of the etch-stopping material leading to low selectivity values. The best reported selectivity for $\mathrm{GaN}$ on $\mathrm{AlN}$ of 38 was obtained using $\mathrm{Cl}_{2} / \mathrm{Ar}$ mixture at $-20 \mathrm{~V}$ bias [27].

Highly anisotropic profiles with smooth sidewalls in GaN have been reported by Shul et al. [25]. A vertical etch profile with ultra-smooth sidewall in InGaN/AlGaN heterostructure obtained with a regrown oxide mask is shown in Fig. 3 [32]. This was obtained using $\mathrm{Cl}_{2} / \mathrm{Ar}$ plasma at 2 mTorr and $-160 \mathrm{~V}$ in a Plasmatherm SLR 790 ICP tool. These results have direct applications to laser facets.

\section{Damage}

Etch-induced damage can be manifested in different forms, all of which may affect the electronic and optical properties of devices fabricated on the etched materials. The forms in which damage can be categorized include: i) deposition of polymer, ii) creation of non-stoichiometric surfaces due to preferential depletion of one of the elements, iii) creation of near-surface lattice defects which can diffuse deep into the sample, and iv) implantation of etching species or hydrogen into the etched material. The few investigations that have been reported in this area measure electrical characteristics of the etched samples. Pearton et al. [35] performed Hall measurements on InN, InGaN, and InAlN exposed to Ar plasma under both ECR and conventional RIE conditions. It was found that the sheet resistances of the samples increased with increasing ion flux and ion energy. Ping et al. [36] investigated the Schottky characteristics of Pd on etched n-GaN layers. The samples were etched by RIE in $\mathrm{SiCl}_{4}$ and Ar plasmas. Etching in $\mathrm{SiCl}_{4}$ plasmas degraded the Schottky barrier heights significantly for self-bias voltages above $-200 \mathrm{~V}$. The barrier height decreased from $0.93 \mathrm{eV}$ to $0.41 \mathrm{eV}$. A more severe degradation to $0.38 \mathrm{eV}$ occurred for Ar plasma at $-100 \mathrm{~V}$. Annealing at $700{ }^{\circ} \mathrm{C}$ was able to restore the barrier height of the $\mathrm{SiCl}_{4}$-etched sample.

The etch-induced degradation was utilized by Fang et al. [37] to improve the ohmic characteristics of $\mathrm{Ti}$ and $\mathrm{Ti} / \mathrm{Al}$ on $\mathrm{n}-\mathrm{GaN}$ layers. The samples were etched by $\mathrm{RIE}$ in $\mathrm{BCl}_{3}$ prior to metal 
deposition. It has also been found that etching with $\mathrm{SiCl}_{4} \mathrm{RIE}$ improved ohmic characteristics under all investigated conditions [38]. This can be explained by the depletion of nitrogen which leaves excess metallic Ga on the etched-surface. This change in stoichiometry renders the surface highly n-type, enhancing ohmic formation while degrading Schottky characteristics. The low bias etching that can be obtained using ICP-RIE and LE4 needs further investigations for realizing etched surfaces with low damage.

\section{WET ETCHING}

Wet etching is an important complement to dry etching methods by providing low damage etching, low cost, and complexity. Conventional wet etching of GaN, AlN, and InN has been studied in base and acid solutions [39-43]. Earlier studies [39] conducted on low quality GaN produced etch rates as high as $1 \mu \mathrm{m} / \mathrm{min}$. However, recent studies by Mileham et al. [40] did not produce any measurable etching for high quality GaN. Slow etch rates have also been recorded for InN. Pearton et al. [41] found that $\mathrm{InN}$ etched very slowly in $\mathrm{HCl} / \mathrm{HNO}_{3}$ solutions. Guo et al. [42] reported etch rates of $\sim 10 \mathrm{~nm} / \mathrm{min}$ for InN using aqueous $\mathrm{KOH}$ and $\mathrm{NaOH}$ solutions at $60{ }^{\circ} \mathrm{C}$. The etching of AlN was found to be highly dependent on the crystallinity of the sample [39]. Etch rates ranging from 10 to $1000 \mathrm{~nm} / \mathrm{min}$ for AlN in $\mathrm{KOH}$ and AZ400K developer solution were reported by Mileham et al. [39,43]. The lower end of the etch rates were obtained for high quality crystalline AlN. It can be concluded that chemical stability exhibited by III-nitrides has resulted in very low etch rates with conventional wet etchants.

\section{Photoelectrochemical wet etching}

A recent development is the demonstration of photoelectrochemical (PEC) wet etching which has resulted in significantly higher etch rates for GaN [44-53]. The PEC process utilizes photogenerated electron-hole pairs to enhance oxidation and reduction reactions taking place in an electrochemical cell. The etching of $n-G a N$ proceeds through surface oxidation followed by dissolution in aqueous solutions. This process is enhanced by the photogenerated holes by converting surface atoms to higher oxidation states. Increasing absorption of incident optical radiation with energy greater than the bandgap energy increase the supply of holes at the surface, thereby enhancing the etch rates.

Minsky et al. [44] first demonstrated PEC etching of $\mathrm{n}-\mathrm{GaN}$ using $\mathrm{KOH} / \mathrm{H}_{2} \mathrm{O}$ and dilute $\mathrm{HCl}$ solutions. They utilized $\mathrm{HeCd}$ laser at $325 \mathrm{~nm}$ wavelength for illuminating $\mathrm{n}-\mathrm{GaN}$ samples at light intensities of $\sim 570$ $\mathrm{mW} / \mathrm{cm}^{2}$. The GaN sample was connected to a $\mathrm{Pt}$ cathode during etching with no external bias applied. Etch rates of $\sim 400 \mathrm{~nm} / \mathrm{min}$ and $40 \mathrm{~nm} / \mathrm{min}$ were obtained for the $\mathrm{KOH}$ and $\mathrm{HCl}$ solutions, respectively. No etching was observed in the absence of optical illumination. Youtsey et al. [45] have demonstrated the etching of $\mathrm{n}-\mathrm{GaN}$ in $\mathrm{KOH}$ solutions using a broad-area $\mathrm{Hg}$ arc lamp. The electrochemical cell utilized by Youtsey et al. [45] is illustrated in Fig. 4. A Pt wire was used as the system cathode and a thin $\mathrm{Ti}(<100 \mathrm{~nm})$ metal was used as the mask. For a $0.04 \mathrm{M} \mathrm{KOH}$ solution

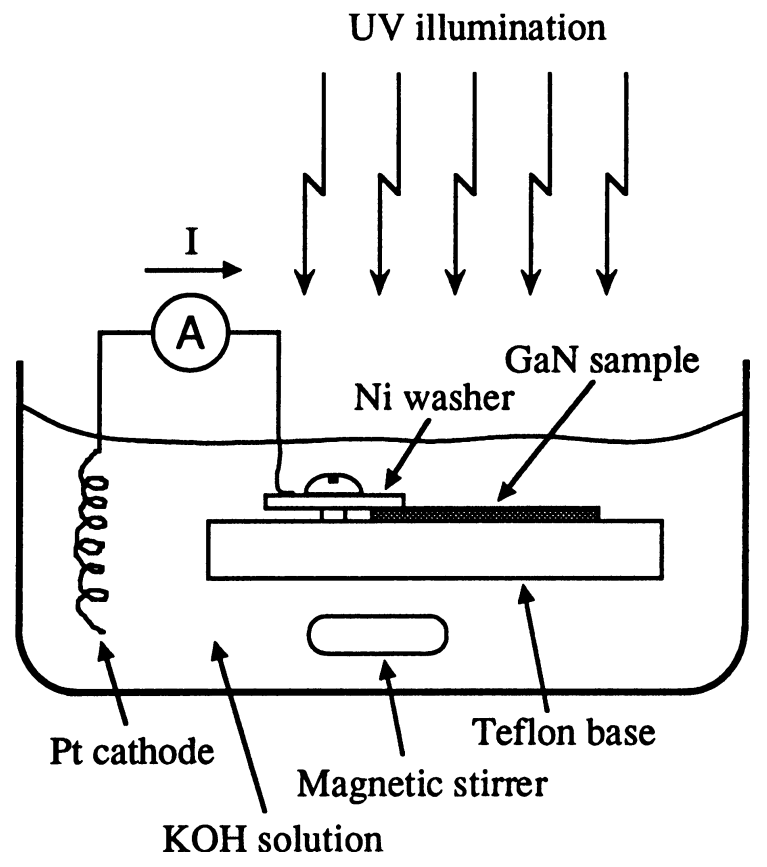

Fig. 4. Photoelectrochemical wet etching apparatus. 
and for light intensities between 10 and 50 $\mathrm{mW} / \mathrm{cm}^{2}$, etch rates were proportional to the light intensity and varied from 50 to 300 $\mathrm{nm} / \mathrm{min}$. Highly anisotropic etch profiles as shown in Fig. 5 were obtained with the rough surfaces attributed to defects in the sample. However, under conditions of very low $\mathrm{KOH}$ concentrations $(<0.01 \mathrm{M})$ and high light intensities, anisotropic etch profiles with very smooth surfaces were obtained by Youtsey et al. [46]. The reaction kinetics in the latter etching is believed to be diffusion-controlled. Using similar etching procedure in $\mathrm{KOH}$ solutions, Cho et al. [47] reported etch rates greater than $100 \mathrm{~nm} / \mathrm{min}$ and an activation energy of $\sim 0.8 \mathrm{kCal} . \mathrm{mol}^{-1}$ under diffusion-

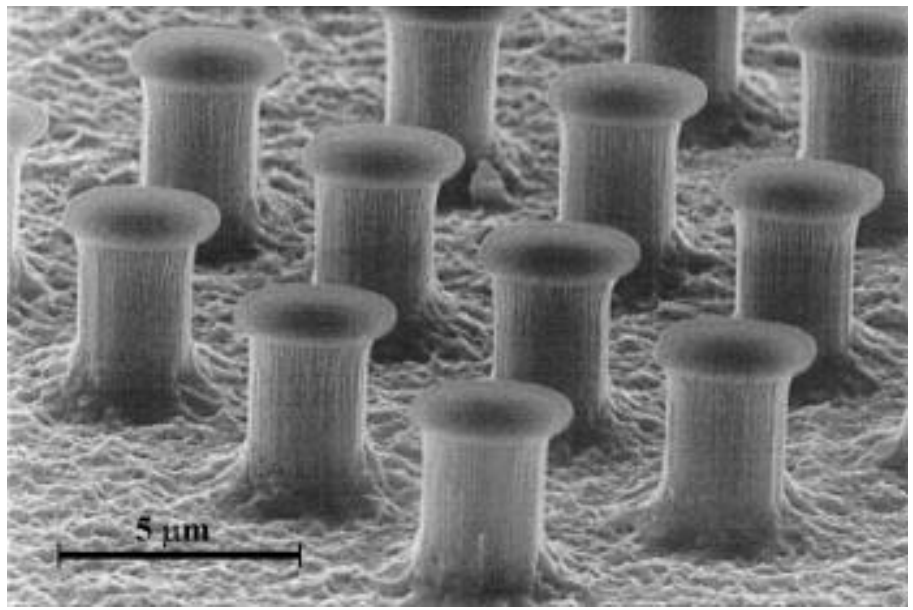

Fig. 5. Highly anisotropic GaN structures by PEC etching controlled kinetics.

$\mathrm{Lu}$ et al. [48] reported on photo-assisted anodic etching of $\mathrm{n}-\mathrm{GaN}$ in solutions of tartaric acid/ethylene glycol at room temperature. Etch rates as high as $160 \mathrm{~nm} / \mathrm{min}$ were obtained for $\mathrm{Hg}$ arc lamp illumination of $\sim 60 \mathrm{~mW} / \mathrm{cm}^{2}$. Etch rates were found to be strongly dependent on the $\mathrm{pH}$ of the solutions. Peng et al. [49] have also reported on the strong $\mathrm{pH}$ dependence of etch rates of $\mathrm{n}-\mathrm{GaN}$ in aqueous $\mathrm{H}_{3} \mathrm{PO}_{4}$ and $\mathrm{KOH}$ solutions. Etch rates as high as $120 \mathrm{~nm} / \mathrm{min}$ were obtained for $\mathrm{H}_{3} \mathrm{PO}_{4}$ solution of $\mathrm{pH}=1$ and $\mathrm{KOH}$ solution of $\mathrm{pH}=14$. Current-controlled PEC etching of $\mathrm{n}-\mathrm{GaN}$ in $\mathrm{KOH}$ solutions under HeCd laser illumination has been reported by Rotter et al. [50]. Etch rates of up to $8 \mu \mathrm{m} / \mathrm{hr}$ were obtained with smooth "mirror-like" etched surfaces.

Youtsey et al. [51] have demonstrated selective PEC etching of $\mathrm{n}-\mathrm{GaN}$ on $\mathrm{p}-\mathrm{GaN}$ in $\mathrm{KOH}$ solutions. No etching was detected for the p-GaN. However, O et al. [52] have demonstrated the etching of $\mathrm{p}-\mathrm{GaN}$ and $\mathrm{InGaN}$ in an LED structure using pulsed electrochemical methods in $\mathrm{H}_{3} \mathrm{PO}_{4} /$ ethylene glycol/ $/ \mathrm{H}_{2} \mathrm{O}$ solutions.

In addition to the etching of $\mathrm{GaN}$ required for device fabrication, it has been shown that PEC can also reveal dislocations in $\mathrm{n}-\mathrm{GaN}$. Rotter et al. [50] observed etch pits with hexagonal symmetry and with a density in the range of $5 \times 10^{9}$ to $1 \times 10^{10} \mathrm{~cm}^{-2}$, corresponding to the dislocation density of the films. Perhaps, the most striking results reported so far in this area pertains to the nanometer-scale

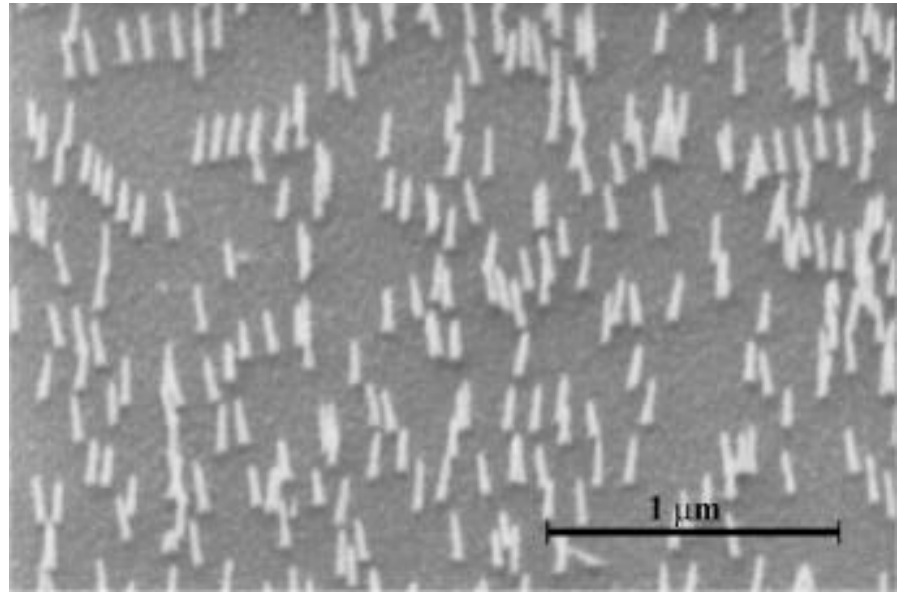

Fig. 6. Nanometer scale whiskers in GaN obtained by PEC etching. "whisker-like" features obtained using borderline diffusion-controlled etching conditions [53]. Figure 6 shows a scanning electron micrograph of "whiskers" obtained by etching $\mathrm{n}-\mathrm{GaN}$ in $0.02 \mathrm{M} \mathrm{KOH}$ with a light intensity of 10 $\mathrm{mW} / \mathrm{cm}^{2}$. The whiskers have diameters of $\sim 25$ $\mathrm{nm}$ and lengths of $\sim 200 \mathrm{~nm}$. Taller whiskers have been produced, however, at heights approaching $1 \mathrm{um}$, they coalesce forming treelike features. Figure 7 (a) shows a crosssectional transmission electron micrograph (TEM) of the whiskers at low magnification. Both the whiskers and dislocations in the underlying unetched $\mathrm{GaN}$ are illustrated. At high magnification, propagation of dislocations from the unetched $\mathrm{GaN}$ into the etched whiskers is 
(a)

(b)
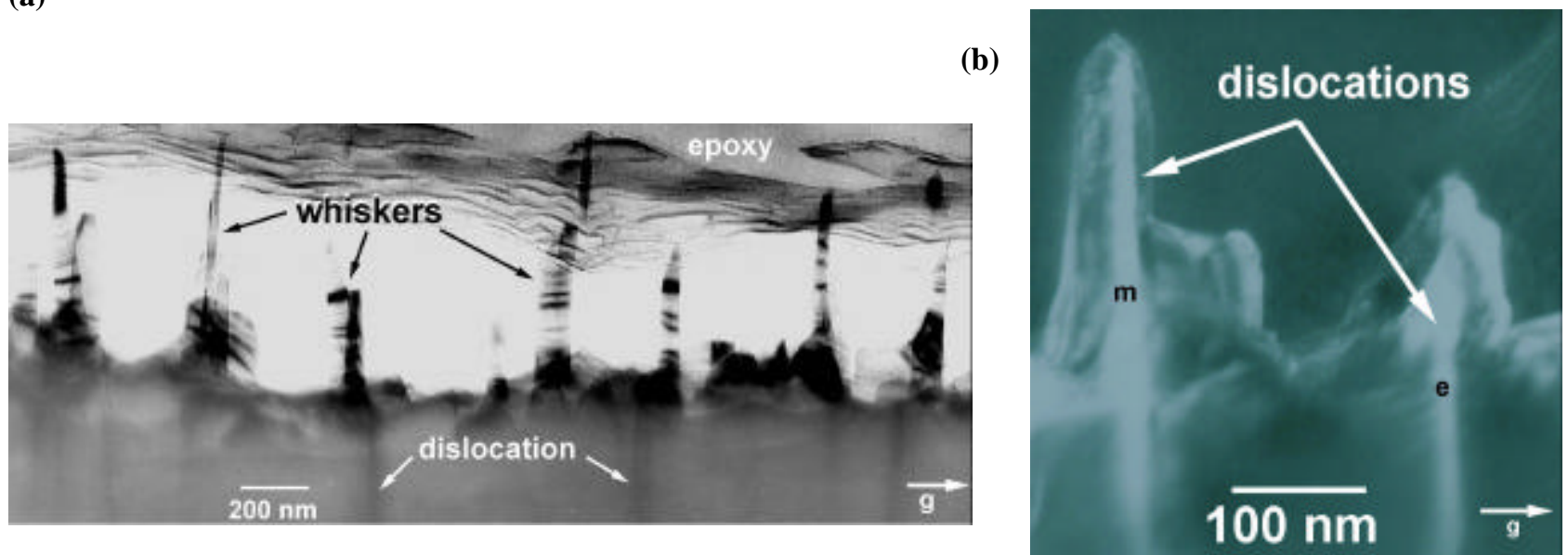

Fig. 7. (a) Cross-sectional TEM of etched GaN with whisker morphology, (b) higher magnification showing propagation of dislocations through the whiskers.

demonstrated in Fig. 7 (b). Both mixed (m) and edge (e) dislocations are associated with whisker formation as shown in the figure. The reduced etch rates at dislocations leading to whisker formation could arise due to a number of different effects [53]. Based on the mechanism of etching, it can be proffered that a spatially varying concentration of photogenerated holes exists on the GaN surface. Weimann et al. [54] have modeled dislocations as negative charged coulombic centers in explaining the low transverse Hall mobilities in $\mathrm{n}-\mathrm{GaN}$. These negative charge centers can become sinks for photogenerated holes thereby locally depressing the concentration of holes that can participate in the etching. This would result in the lateral selective etching of the crystalline over dislocation areas in the $\mathrm{n}-\mathrm{GaN}$.

As seen, under certain PEC etching conditions, dislocations are isolated on $\mathrm{n}$ GaN. With the diameter of individual dislocation "whiskers" less than $50 \mathrm{~nm}$, a plan view of a dislocation in a scanning electron microscope will be a spot or dot. Therefore an aerial image over a large area will result in the "star map" as shown Fig. 8. The counting of dots in a fixed area of the map yields the dislocation density of the material. Figure 8 shows the dislocation

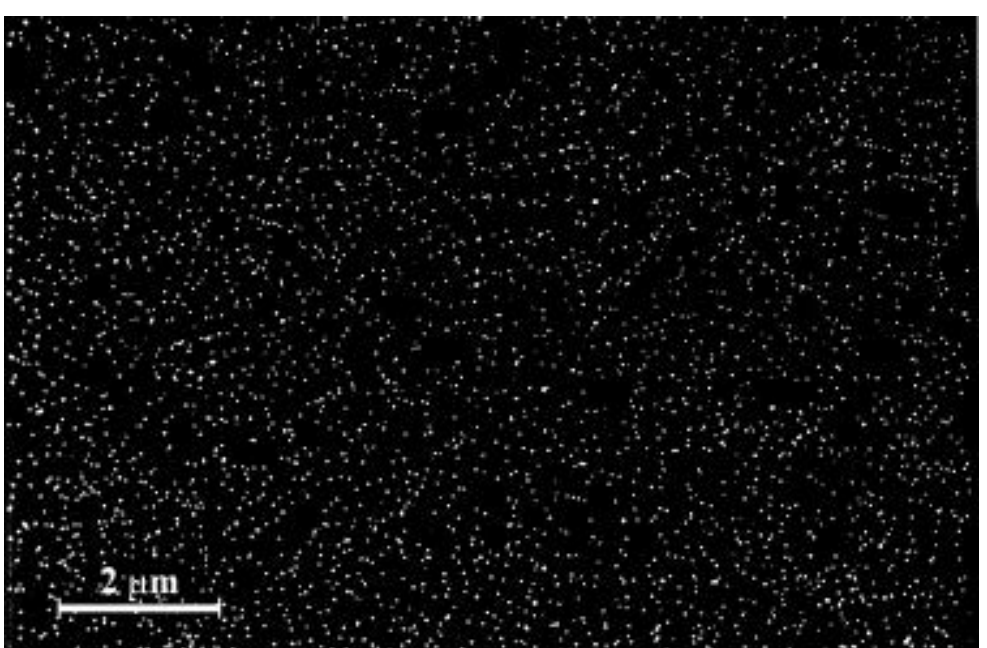

Fig. 8. 'Star map' of dislocations in GaN on SiC. grown $\mathrm{n}-\mathrm{GaN}$ on $\mathrm{SiC}$. The sample was grown n-GaN on SiC. The sample was light intensity for $15 \mathrm{~min}$. The dislocation density is estimated from the figure to be $3.2 \times 10^{9} \mathrm{~cm}^{-2}$. This estimation has been verified using TEM. It is seen that PEC method can be utilized for a rapid evaluation of dislocation densities in $\mathrm{n}-\mathrm{GaN}$ materials. This method is less tedious than the conventional TEM method of assessing dislocation densities. 


\section{SUMMARY}

Dry and wet etching methods for III-nitrides have been reviewed. Although the high bonding energies have constituted obstacles to the etching of the nitrides, high-density-plasma etching methods have yielded etch rates that are suitable for device fabrication. The low bias voltages enabled by these high-density-plasma etching methods should allow low damage etching of nitride surfaces. More efforts are required in this area to quantify the processing latitude provided by techniques such as the ICP-RIE. The photoelectrochemical etching method has been shown to be an emerging method for device fabrication and material characterization. The PEC was shown to have the potential of becoming a rapid evaluation tool for dislocations in $\mathrm{n}-\mathrm{GaN}$.

\section{ACKNOWLEDGMENTS}

This work was supported by at the University of Illinois by NSF grant No ECS 95-21671 and DARPA Grant No. F19628-96-C-0066; at CREE Research by DARPA Grant No. F19628-96-C-0066; and at Xerox by DARPA Grant No. MDA972-96-3-0014.

\section{REFERENCES}

[1] S. Nakamura, T. Mukai, and M. Senoh, Appl. Phys. Lett. 64, 1687 (1994).

[2] S. Nakamura, M. Senoh, S. Nagahama, N. Iwasa, T. Yamada, T. Matsushita, H. Kiyoku, and S. Sugimoto, Appl. Phys. Lett. 68, 2105 (1996).

[3] A. T. Ping, I. Adesida, K. Boutros, and J. Redwing, unpublished.

[4] S. Sheppard, K. Doverspike, W. Pribble, S. Allen, J. Palmour, L. Kehias, T. Jenkins, Paper V.B.5, Device Research Conference (Charlolltesville, VA, 1998).

[5] L. McCarthy, P. Kozodoy, M. Rodwell, S. DenBaars, and U. Mishra, Compound Semiconductor 4 (8), 16 (1998).

[6] I. Adesida, A.T. Ping, C. Youtsey, T. Dow, M. Asif Khan, D.T. Olson, and J.N. Kuznia, Appl. Phys. Lett. 65, 889 (1994).

[7] S.J. Pearton, C.R. Abernathy, F. Ren, and J.R. Lothian, J. Appl. Phys 76, 1210 (1994).

[8] A.T. Ping, I. Adesida, and M. Asif Khan, Appl. Phys. Lett. 67, 1250 (1995).

[9] A.T. Ping, C. Youtsey, I. Adesida, M. Asif Khan, and J.N. Kuznia, J. Electron. Mat. 24, 229 (1995).

[10] J.-W. Lee, H.-S. Park, Y.-J. Park, M.-C. Yoo, T.-I Kim, H.-S. Kim, and G.-Y. Yeom, MRS Symp. Proc. 468, 373 (1997).

[11] D. Basak, M. Verdú, M.T. Montojo, M.A. Sánchez-García, F.J. Sánchez, E. Munoz, and E. Calleja, Semicond. Sci. Tech. 12, 1654 (1997).

[12] H. Lee, D.B. Oberman, and J.S. Harris Jr, Appl. Phys. Lett. 67, 1754 (1995).

[13] I. Adesida, A. Mahajan, E. Andideh, M. Asif Khan, D.T. Olson, and J.N. Kuznia Appl. Phys. Lett. 63, 2777 (1993).

[14] A.T. Ping, I. Adesida, M. Asif Khan, and J.N. Kuznia, Electron. Lett. 30, 1895 (1994).

[15] M.E. Lin, Z.F. Fan, Z. Ma, L.H. Allen, and H. Morkos, Appl. Phys. Lett. 64, 887 (1994).

[16] S.J. Pearton, C.R. Abernathy, F. Ren, J.R. Lothian, P.W. Wisk, and A. Katz, J. Vac. Sci. Technol. A 11, 1772 (1993).

[17] S.J. Pearton, C.R. Abernathy, and C.B. Vartuli, Electron. Lett. 30, 1985 (1994).

[18] L. Zhang, J. Ramer, J. Brown, K. Zheng, L.F. Lester, and S.D. Hersee, Appl. Phys. Lett. 68, 367 (1996). 
[19] R.J. Shul, S.P. Kilcoyne, M.H. Crawford, J.E. Parmeter, C.B. Vartuli, C.R. Abernathy, and S.J. Pearton, Appl. Phys. Lett. 66, 1761 (1995).

[20] C.B. Vartuli, S.J. Pearton, J.W. Lee, J.D. MacKenzie, C.R. Abernathy, and R.J. Shul, J. Vac. Sci. Technol. B 15, 98 (1997).

[21] C.B. Vartuli, S.J. Pearton, J.W. Lee, J. Hong, J.D. MacKenzie, C.R. Abernathy, and R.J. Shul, Appl. Phys. Lett. 69, 1426 (1996).

[22] H. Cho, C.B. Vartuli, S.M. Donovan, J.D. Mackenzie, C.R. Abernathy, S.J. Pearton, R.J. Shul, and C. Constantine, J. Electron. Mat. 27, 166 (1998).

[23] R.J. Shul, C.G. Willison, M.M Bridges, J. Han, J.W. Lee, S.J. Pearton, C.R. Abernathy, J.D. Mackenzie, S.M. Donovan, L. Zhang, and L.F. Lester, J. Vac. Sci. Technol. A 16, 1621 (1998).

[24] C.B. Vartuli, J.W. Lee, J.D. MacKenzie, S.M. Donovan, C.R. Abernathy, S.J. Pearton, R.J. Shul, C. Constantine, C. Barratt, A.Y. Poyakov, M. Shin, M. Skowronski, Mat. Res. Soc. Symp. Proc. 468, 393 (1997).

[25] R.J. Shul, G.B. McClellan, S.A. Casalnuovo, D.J. Rieger, S.J. Pearton, C. Constantine, C. Barratt, R.F. Karlicek Jr., C. Tran, and M. Schurman, Appl. Phys. Lett. 69, 1119 (1996).

[26] Y.H. Lee, H.S. Kim, G.Y. Yeom, J.W. Lee, M.C. Yoo, and T.I. Kim, J. Vac. Sci. Technol. A 16, 1478 (1998).

[27] S.A. Smith, C.A Wolden, M.D. Bremser, A.D. Hanser, R.F. Davis, and W.V. Lampert, Appl. Phys. Lett. 25, 3631 (1997).

[28] R.T. Leonard and S.M. Bedair, Appl. Phys. Lett. 68, 794 (1996).

[29] H.P. Gillis, D.A.Choutov, K.P. Martin, M.D. Bremser, and R.F. Davis, J. Electron. Mat. 26, 301 (1997).

[30] M. Kneissl, D.P. Bour, N.M. Johnson, L.T. Romano, B.S. Krusor, R. Donaldson, J. Walker, and C. Dunnrowicz, Apl. Phys. Lett. 72, 1539 (1998).

[31] F. Binet, J.Y. Duboz, N. Laurent, C. Bonnat, P. Collot, F. Hanauer, O. Briot, and R.L. Aulombard, Apl. Phys. Lett. 72, 960 (1998).

[32] F. Khan, C. Youtsey, and I. Adesida, unpublished.

[33] H. Cho, C. Vartulli, S. Donovan, C. Abernathy, S. Pearton, R. Shul, and C. Constantine, J. Vac. Sci. Technol. A16, 1631 (1998).

[34] R. Shul, C. Willison, M. Bridges, J. Han, J. Lee, S. Pearton, C. Abernathy, J. MacKenzie, S. Donovan, L. Zhang, and L. Lester, J. Vac. Sci. Technol. A16, 1631 (1998).

[35] S.J. Pearton, J.W. Lee, J.D. MacKenzie, C.R. Abernathy, and R.J. Shul, Appl. Phys. Lett. 67, 2329 (1995).

[36] A.T. Ping, A.C. Schmitz, M. Asif Khan, Q. Chen, J.W. Yang, and I. Adesida, J. Electron. Mater. 26, 266 (1997).

[37] Z. Fang, S.N. Mohammad, W. Kim, O. Aktas, A.E. Botchkarev, and H. Morkos [Appl. Phys. Lett. (USA) vol.68 (1996) p.1672]

[38] A.T. Ping, Q. Chen, J.W. Yang, M.Asif Khan, and I. Adesida, J. Electron. Mater. 27, 261 (1998).

[39] Y. Morimoto, J. Electrochem. Soc.121, 1384 (1974).

[40] J.R. Mileham, S.J. Pearton, C.R. Abernathy, J.D. MacKenzie, R.J. Shul, and S.P. Kilcoyne, J. Vac. Sci. Technol. A14, 836 (1996).

[41] S. Pearton, C. Abernathy, F. Ren, J. Lothian, P. Wisk, and A. Katz, J. Vac. Sci. Technol. 11, 1772 (1993).

[42] Q.X. Guo, O. Kato, and A. Yoshida, J. Electrochem. Soc. 139, 2008 (1992).

[43] J.R. Mileham, S.J. Pearton, C.R. Abernathy, and J.D. MacKenzie, Appl. Phys. Lett. 67, 1119 (1995)

[44] M.S. Minskey, M. White, and E.L. Hu, Appl. Phys. Lett. 68, 1531 (1996).

[45] C. Youtsey, I. Adesida, and G. Bulman, Appl. Phys. Lett. 71, 2151 (1997).

[46] C. Youtsey, I. Adesida, L.T. Romano, and G. Bulman, Appl. Phys. Lett. 72, 560 (1998). 
[47] H. Cho, K. Auh, R. Shul, S. Donovan, C. Abernathy, E. Lambers, F. Ren, and S. Pearton, J. Electron. Mater. (in press).

[48] H. Lu, Z. Wu, and I. Bhat, J. Electrochem. Soc. 144, L8 (1997).

[49] L. -H. Peng, C. Chuang, J. Ho, C. Huang and C.-Y. Chen, Appl. Phys. Let. 72, 939 (1997)

[50] T. Rotter, D. Uffmann, J. Ackermann, J. Aderhold, J. Stemmer, and J. Graul Mat. Res. Soc. Symp. Proc. 482 (1997).

[51] C. Youtsey, I. Adesida, and G. Bulman, J. Electron. Mater. 27, 282 (1998).

[52] J. O, P.S. Zory and D.P. Bour, SPIE Proc. 3002, 117 (1997).

[53] C. Youtsey, L.T. Romano, and I. Adesida, Appl. Phys. Lett. 73, 797 (1998).

[54] N.G. Weimann, L.F. Eastman, D. Doppalapudi, H.M. Ng and T.D. Moustakas, J. Appl. Phys. 83, 3656 (1998).

[55] A.T. Ping, M. Asif Khan, and I. Adesida, Semicond. Sci. Technol. 12, 133 (1997). 